\title{
ACUTE AND CATASTROPHIC REACTIVATION OF CHRONIC LYMPHATIC LEUKEMIA AFTER CARDIAC SURGERY
}

\author{
Cegarra-Sanmartin V, Miralles J, Font A, Felipe M, Galan J, Moral MV \\ Hospital de la Santa Creu i Sant Pau, Dept of Anaesthesiology. Barcelona (Spain)
}

\section{Background}

Chronic lymphatic leukemia (CLL) is a common disease among elderly individuals with proliferation of incompetent lymphocytes and accumulation in the bone marrow, liver,spleen and lymph nodes. The estimated survival depends on clinical and laboratory values.

Cardiopulmonary bypass (CBP) and surgical trauma cause activation of the inflammatory response. This results in changes in counts and properties of lymphocytes that can cause an unpredictable course.

\section{Case Report}

A-78-years-old woman was referred for mitral and aortic valve replacement for increase of her dyspnea and NYHA class. Medical history included aortic valve replacement 10 years before for rheumatic degeneration, hypertension, dyslipidemia, chronic atrial fibrillation and CLL-B (stage Binet C) treated with chlorambucyl until 6 months before.

Preoperative investigations revealed: $70 \%$ of infiltration of the bone marrow (biopsy) and $90 \%$ infiltration in myelogram. Laboratory values (Table 2).

Double valve replacement was performed with mechanical prosthesis. The patient came off CPB easily but early in postoperative time had a major bleeding requering massive transfusion, with low output state, acute renal injury and lower respiratory tract infection. Stability was achieved by fourth day postoperative and she was returned to the ward on anticoagulation with UFH. By fifth day, WBC achieved a total count of 56.940x10\%/L (lymphocytes $43.720 \times 10^{9} / \mathrm{L}$ ) and no treatment was ordered because of lack of symptoms.

Late on the eleventh postoperative day, her condition deteriorated to acute pulmonary oedema. Echocardiogram showed an acute right ventricular failure and a severe increase of median transmitral gradient (25mmHg). Pulmonary catheter revealed C.I $1.4 \mathrm{~L} / \mathrm{min} / \mathrm{m}^{2}$ and a pulmonary capillary wedge pressure of $40 \mathrm{mmHg}$. Laboratory investigation showed $185 \times 10^{9} / \mathrm{L}$ of lymphocytes. An acute reactivation of CLL was diagnosed with early thrombosis of the mitral prosthesis and the patient died some hours later.

Figure 1. Clinical evolution

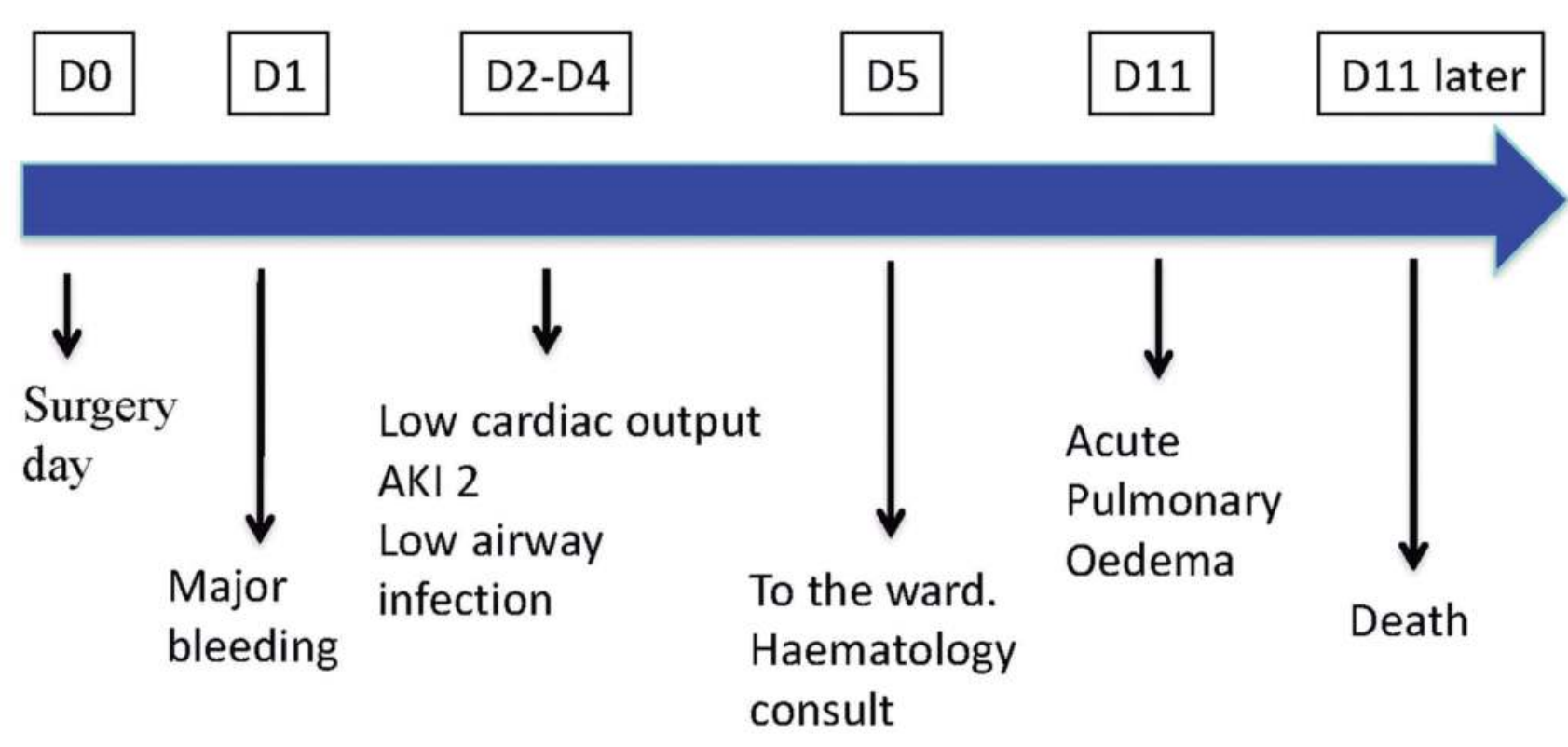

Table 2. Laboratory values

\begin{tabular}{|l|c|c|c|c|c|c|}
\hline & Basal & D1 & D5 & D7 & D10 & D11 \\
\hline $\begin{array}{l}\text { WBC } \\
(\mathbf{x ~ 1 0} / \text { /L) }\end{array}$ & 17.5 & 26 & 57 & 87 & 147 & 213 \\
\hline $\begin{array}{l}\text { Lymphocy } \\
\left(\times 10^{9} / \text { L) }\right.\end{array}$ & 14 & 18.6 & 44 & 70 & 125 & 186 \\
\hline $\begin{array}{l}\text { Hemog } \\
\text { (g/dl) }\end{array}$ & 9.0 & 7.6 & 8.6 & 9.2 & 9.5 & 9.8 \\
\hline $\begin{array}{l}\text { Platelet } \\
\text { count } \\
\text { (x 109/L) }\end{array}$ & 106 & 62 & 99 & 194 & 267 & 276 \\
\hline
\end{tabular}

\section{Discussion}

Good postoperative outcomes in CLL patients have been reported. Main complications are coagulation disorders and infection. Inflammatory stress of surgery and response to CPB are unpredictable. A good preoperative analysis of the CLL status and carefully monitoring of WBC are required to avoid catastrophic resuts. 